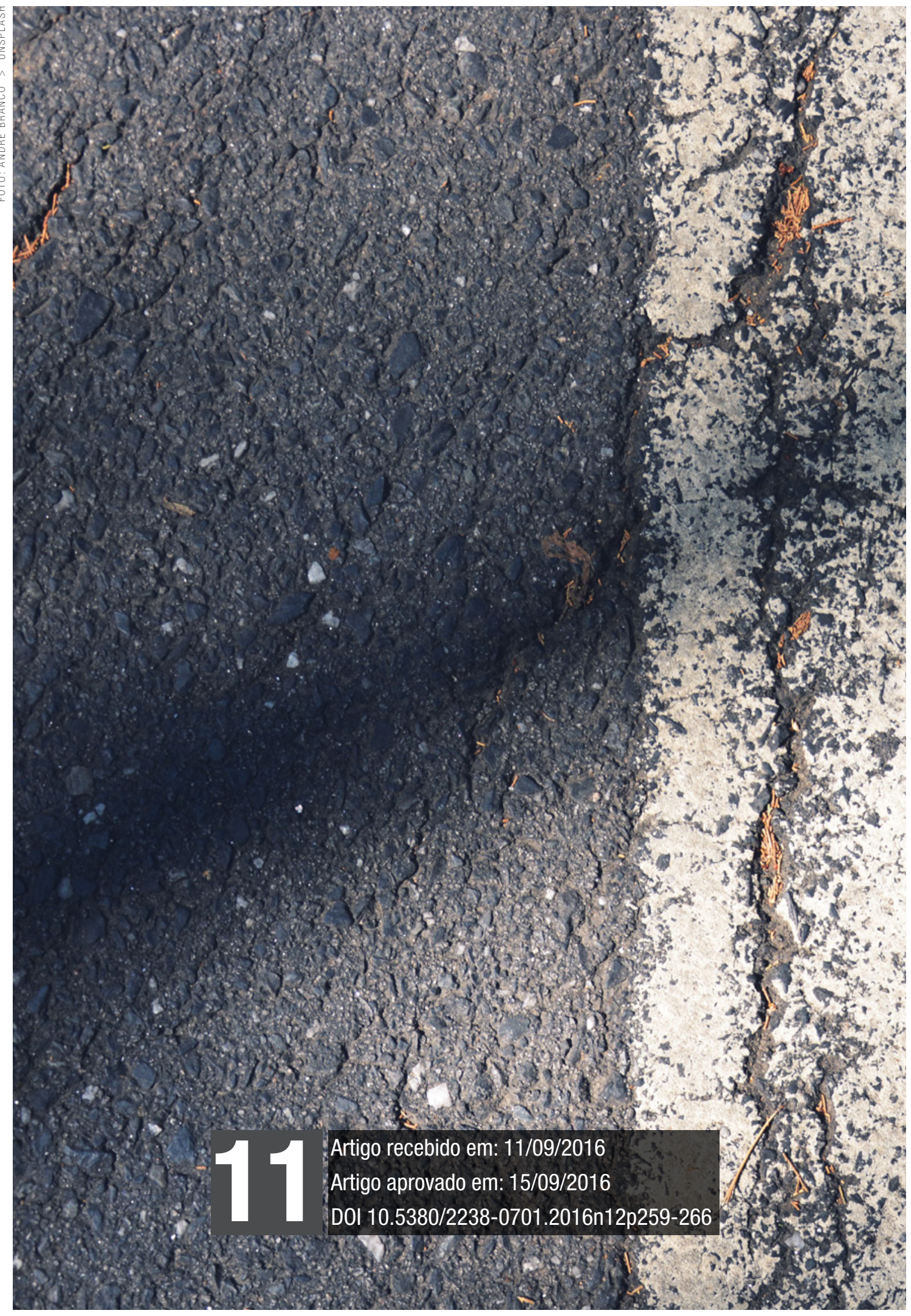


Massive Open Online Course (MOOC) 


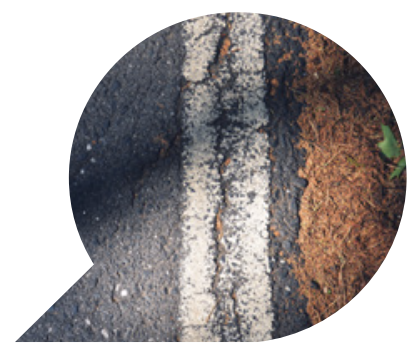

\title{
MOOC: as condições do sucesso ${ }^{1}$
}

\author{
MOOC: les conditions de la réussite
}

MOOC: conditions for success

\section{MATTHIEU CISEL ${ }^{2}$}

"MOOCs ${ }^{3}$ são um produto sujo" ou, na língua de Molière, "os MOOCs são um produto de segunda categoria”. É nestes termos pouco animadores que falava, há cerca de um ano, Sebastian Thrun (SCHUMANN, 2013). Uma afirmação que surpreendeu muita gente, quando se sabe que ele foi um dos fundadores do movimento MOOC e que seu curso de inteligência artificial, primeiro do gênero, foi procurado por cerca de 160.000 estudantes (CISEL; BRUILLARD, 2012). Afirmação ainda mais surpreendente se lembrarmos de que ele lançou em 2012 a plataforma Udacity, de cursos online e em pleno desenvolvimento. Esta reviravolta se justifica, de acordo com ele, pelas altas taxas de fracasso observadas num dos MOOC da Udacity, por um público composto, na sua maior parte, por alunos em dificul-

1 Tradução de Rosa Maria Cardoso Dalla Costa e Armando Dalla Costa.

2 ENS Cachan, STEF, mcisel@ens-cachan.fr

3 Curso Online Aberto e Massivo, do inglês Massive Open Online Course (MOOC), é um tipo de curso aberto ofertado por meio de ambientes virtuais de aprendizagem, que visa oferecer para um grande número de alunos a oportunidade de ampliar seus conhecimentos num processo de co-produção. Trata-se de um desenvolvimento recente na área de educação a distância e uma progressão dos ideais de educação aberta. Embora o projeto e participação em um MOOC possa ser semelhante ao de um curso em uma faculdade ou universidade, os MOOCs normalmente são gratuitos e não exigem pré-requisitos, mas também não oferecem certificados de participação (Nota dos tradutores). 
dade. A polêmica instaurada por esta frase destaca a importância de definir o que é o sucesso de um MOOC e, de compreender melhor as condições nas quais ele se realiza.

Todos estão de acordo num sentido, que o sucesso de um MOOC, idealmente, deveria ser medido por aquilo que foi conseguido em termos de aprendizagem, compreensão e apropriação do conhecimento. Entretanto, a tarefa é particularmente árdua, uma vez que não existe avaliação individual, dificultada pelo tanto de participantes. Não saberíamos determinar o aprendizado a partir de quanto material que foi consultado. Esta frase de Justin Reich a respeito das pesquisas sobre os MOOC resume à perfeição a situação: "Nós temos uma grande quantidade de terabytes de clicks, mas uma compreensão imperfeita daquilo que mudou na cabeça das pessoas" (REICH, 2014). Tais considerações não devem, entretanto, nos desviar de nosso foco; uma medida do sucesso - mesmo que imperfeita - é necessária se desejamos determinar a pertinência dos investimentos feitos na concepção destes cursos.

$\mathrm{O}$ erro recorrente consiste em querer empregar os indicadores de sucesso que só são pertinentes no quadro de formações onde o público é cativo. O uso do termo "taxa de abandono" é um exemplo típico. $\mathrm{O}$ termo "abandono" sugere que se teve a intenção de terminar a formação, uma hipótese muito discutível, tendo em vista como é feito o processo de inscrição (DANIEL, 2012). A escolha dos critérios de sucesso é ainda mais difícil de medir se levarmos em consideração que a pertinência de um indicador depende, antes de tudo, da escolha pedagógica seguida e da intenção da equipe que está ofertando o curso. Desta forma, para os MOOCs centrados em conteúdos, o número de vídeos assistidos será, sem dúvida, o indicador mais pertinente, enquanto que para os MOOCs centrados sobre a interação, o volume de troca de mensagens entre os participantes será o parâmetro mais interessante. É necessário, portanto, analisar caso a caso, adotar atitudes multi-indicadores e precaver-se de todo julgamento prévio.

Antes de continuar sobre as condições do sucesso, vamos começar por continuar algo já começado. Independente da maneira que seja definido, o sucesso de uma formação está intimamente ligado ao público que a segue. O processo de aprendizagem é uma co-construção cuja responsabilidade é dividida entre aquele que ensina e o que aprende. S. Thrun subentende pela tomada de posição, que o processo depende, antes de tudo, da qualidade do "produto" que utiliza o 
professor. Além de ser discutível sob o ponto de vista científico, de querer generalizar a partir de uma experiência única, esta postura demonstra uma mentalidade típica dos empreendedores do Vale do Silício e que Evgeny Morozov chama de 'solucionismo' tecnológico (MOROZOV, 2014). Tal solução é uma postura que consiste em pensar que todos os males do mundo podem ser resolvidos via soluções tecnológicas. O erro fundamental consiste aqui em fazer uma mistura entre informação e conhecimento. Disponibilizar ao aprendiz no momento certo a informação ou a atividade a mais pertinente, é um desafio, certo, mas que pode ser solucionado via tecnologia. Por outro lado, a assimilação desta informação e sua integração sob a forma de conhecimento, pessoal e não transferível por definição, é outra questão. Esta segunda parte fica por conta daquele que se propõe a aprender. É um fenômeno que, felizmente, escapa ao controle da equipe pedagógica. Isso nos remete à importância de pensar as questões motivacionais, os desafios, os conhecimentos e competências pré-existentes, o contexto no qual estamos inseridos, pois estes parâmetros próprios dos participantes têm, certamente, uma influência sobre a eficácia do curso (BRUILLARD, 2014).

A influência das características da audiência dos MOOCs sobre as dinâmicas observadas torna difícil identificar os fatores na ordem de importância. A análise é dupla: de um lado precisamos nos debruçar sobre a influência das características ligadas aos participantes sobre os seus comportamentos - utilizaremos, por exemplo, dados conseguidos via questionários para melhor compreender o público - e, de outro lado, devemos estudar os fatores ligados aos dispositivos pedagógicos. Neste último caso, é difícil tirar conclusões robustas simplesmente comparando diversos dispositivos de formação, ou mesmo comparando duas edições sucessivas e ligeiramente distintas do mesmo curso. Isto se deve aos efeitos que podem nos levar a avaliações qualitativas e quantitativas sobre a audiência do curso. Se a análise de experiências práticas permite contornar alguns obstáculos quando aplicada a determinadas situações, ela mostra também, rapidamente, seus limites.

O processo de identificação das condições de sucesso comporta, necessariamente, uma parte de interpretação. A importância do assunto e a complexidade do problema levaram-me a escolher esta situação como tema de minha pesquisa na tese de doutorado. Após anos de análise dos cursos de formação, quero assegurar àqueles que 
temem que as tecnologias da educação e as pesquisas em ciências da educação favorecem a emergência de uma nova forma de taylorismo pedagógico, que não é bem assim (RENAUD, 2014). A tecnologia não irá rebaixar os professores à tarefa de simples executores, aplicando mecanicamente as receitas estabelecidas pelos escritórios pedagógicos. Isso simplesmente porque existe um componente humano nos cursos de formação que escapa, largamente, a toda predisposição científica. $\mathrm{O}$ uso de ferramentas aperfeiçoadas e a pesquisa de boas práticas não é incompatível com certa forma de 'artesanato', bem ao contrário.

Para concluir, gostaria de lembrar que a identificação dos critérios de sucesso implica, antes de tudo, definir precisamente o objetivo da pesquisa. Em função da crise econômica pela qual passam muitos estabelecimentos de ensino superior, não podemos simplesmente justificar o investimento nos MOOCs, às vezes onerosos, pela simples e boa razão que devemos seguir a tendência. Alguns juram com a convicção dos "cristãos novos" que a democratização do acesso ao conhecimento permanece como o objetivo principal. Estas convicções podem nos levar ao engano, quando conhecemos a tradição de elitismo secular reivindicada por muitos destes estabelecimentos. Outros não escondem o caráter promocional deste novo modelo de ensino, nem a busca de retomadas simbólicas ou econômicas; estes, destacando a necessidade de renovar a pedagogia universitária tendo como base a revolução da informática.

Não colocamos em dúvida a boa intenção das motivações que não são, aliás, exclusivas, mas insistimos sobre a necessidade de clarear as intenções subjacentes ou pré-determinadas. $\mathrm{Na}$ ausência de objetivos claros e compartilhados, o fenômeno MOOC corre o risco de não sobreviver e as restrições monetárias acabarão por se impor às outras razões. O desenvolvimento tecnológico progride e definir objetivos claros não é tão simples como parece. É necessário, nada mais nada menos que redefinir a missão dos estabelecimentos de serviço público na era da informática. O simples fato de tornar possível a formação, a custos razoáveis, de um grande número de pessoas, significa que devemos, necessariamente, fazê-lo? Este debate é, infelizmente, repetido à exaustão, fazendo com que se esqueçam os bons motivos que nos levam a colocar em prática, de fato, a educação.

A questão das condições de sucesso é igualmente crítica, pois a boa vontade, sozinha, não garante sobrevivência no mundo da in- 
ternet. Apesar de numerosas experiências feitas, a Web pedagógica permanece, em larga medida, uma terra estranha. É frequente que se chegue a resultados frustrantes com ótimos projetos. Faz-se necessário, portanto, uma boa compreensão dos fatos e das expectativas, para não cair em decepções profundas. O risco é "jogar fora o bebê com a água do banho" na falta de resultados espetaculares e que os MOOCs terminem no Panteão das tecnologias que devem revolucionar para sempre a educação e a formação.

O fenômeno encontra-se somente na sua pré-história. As tecnologias empregadas são ainda rústicas e os conhecimentos científicos começam apenas a tomar forma. É necessário dar tempo ao tempo e continuar a progredir lentamente, mas com segurança. Apesar das críticas que lhe são feitas, os MOOCs já desempenharam seu papel na tomada de consciência das potencialidades da informática na educação. Não deem muita atenção, portanto, às frases pejorativas como as de Sebastian Thrun. Sua tomada de posição reflete mais uma estratégia comercial - sua startup distancia-se dos MOOCs para propor formações pagas destinadas às empresas - que uma verdade científica construída.

Assim como já foi dito por outros autores (BOULLIER, 2014), eu também penso que os MOOCs atuais não representam nem uma revolução tecnológica, nem uma revolução pedagógica. Entretanto, permitiram-nos entrar plenamente numa nova era da formação, aquela da abertura educativa, da educação aberta e gratuita para todos. De um jeito ou de outro, este fenômeno informal e marginal até a pouco, não vai parar de crescer. Com a conscientização coletiva feita, duvido que haja um movimento de volta pura e simples ao passado. Ano após ano a internet continuará, inexoravelmente, a contribuir para o acesso a uma educação de qualidade e sempre atingindo mais público. A questão que se coloca, no momento, é a do papel que deverão ter os estabelecimentos de ensino superior públicos nesta mudança. A democratização da educação e a questão da igualdade de oportunidades apresentam-se como valores máximos de nosso serviço público e seria uma pena se, diante deles, nos comportássemos como simples expectadores desta evolução. 


\section{REFERÊNCIAS}

BOULLIER, D. MOOC: en attendant l'innovation. In: Distances et médiations des saviors. Acessado 01 dezembro 2014. URL : http://dms.revues.org/685

BRUILLARD, E.. Les utilisateurs des MOOC: quel regard? In: Distances et médiations des saviors. Acesso 01 dezembro 2014. URL : http://dms.revues. org/791

CISEL, M.; BRUILLARD, E. Chronique des MOOC. Rubrique de la revue STICEF, vol. 19, 2012. [Disponível em] http://sticef.org

DANIEL, J. Making Sense of MOOCs: Musings in a Maze of Myth, Paradox and Possibility. In: Journal of Interactive Media in Education (JIME), 2012. [Disponível em] http:77jime.open.ac.uk/2012/18

MOROZOV, E. To save everything, click here: Technology, Solutionism, and the Urge to Fix Problems that Don't Exist. 2014

REICH, J. MOOCs and the Science of Learning. Education Week. Acessado 01 dezembro 2014. [Disponível em] http://blogs.edweek.org/edweek/ edtechresearcher/2014/07/moocs_and_the_science_of_learning.html?cmp=ENLEU-NEWS3

RENAUD, E. Non au taylorisme pédagogique. 2014 [Disponível em] http://mediateur.blog.lemonde.fr/2013/12/19/non-au-taylorisme-pedagogique/

SCHUMAN, R. The King of MOOCs abdicates the Throne. [Disponível em] http://www.slate.com/articles/life/education/2013/11/sebastian_thrun_and_ udacity_distance_learning_is_unsuccessful_for_most_students.html 